\title{
Risk Management and Performance of Small and Medium Enterprises in Osun State, Nigeria
}

\author{
Taofeek Sola Afolabi \\ Department of Financial Studies, \\ Redeemer's University, Ede, Osun state, Nigeria \\ Joseph Tugudu James \\ Department of Financial Studies, \\ Redeemer's University, Ede, Osun state, Nigeria
}

\begin{abstract}
Small and Medium Enterprises (SMEs) in both developing and developed economies play crucial roles in economic development through wealth creation, employment opportunities and poverty alleviation. However, the uncertainties surrounding businesses require SMEs to effectively manage their risk exposures. This study examined the influence of risk management practices on the performance of SMEs in Osun state, south-western Nigeria. A total of 340 SME operators in the state were chosen for this study and primary data were collected through a structured questionnaire which was administered to managers/operators of the selected SMEs. A total of 330 copies of the questionnaire were returned having been correctly filled and deemed suitable for this research. A linear regression model, through the Ordinary Least Squares technique was used for the data analysis and test for hypothesis, with the aid of the E-view statistical software. The result from the analysis revealed a significant relationship between risk management and the performance of SMEs ( $t$-value=23.47; p $<0.05)$. The result further showed that attitude to risk positively affects risk management practices and that there is a strong positive correlation between risk identification and risk management $(r=0.92)$. The study therefore concluded that risk management practices have significant and positive influence on the performance of SMEs in Osun state. It was recommended that SME operators in Nigeria should put in place cost-effective measures for timely risk identification and effective risk mitigation in order to ensure that their financial performance is not negatively impacted.
\end{abstract}

Keywords: Insurance, Risk management, Small and medium enterprises.

\section{INTRODUCTION}

The importance of Small and Medium Enterprises (SMEs) as engine of growth in both developed and developing countries has been identified by many scholars (Odah, 2005; Agwu \& Emeti, 2013; Alese, 2017). According to Kuteyi (2013), SMEs drive their country's development as they create employment and contribute to the gross domestic product (GDP). They play crucial roles in economic development through wealth creation, employment opportunities and poverty alleviation. SME has been given different definitions in literature, such as an organization with employees less than 50, between 10 and 50, or less than 250 (World bank, 2001; European Commission, 2006). The fact is that SMEs operate in the same environment as their larger counterparts, but without the associated benefits such as adequate capital and extended human resources of the larger organizations. However, to remain competitive requires regular policy review and development of the new business approaches, which often come with their associated risk (Spedding \& Rose, 2008). Given the complexities surrounding business enterprise, the effort to deal with risk exposures has become crucial to SMEs' (Boniface \& Ibe, 2012). SMEs continue to face heightened instability from the effect of globalization, deregulations, and intensive competitions (Shecterle, 2010). As such, their 
failure to be proactive in risk assessment, mitigation and control had resulted in poor firm performance.

According to Inang and Ukpong (2002) and Aruwa (2004b) cited by Terungwa (2012), risk is one of the recurrent problems that makes SMEs unattractive to investors. Risk is defined as the uncertainty of loss. Businesses encounter many risks. SMEs are businesses in the private sector and they cut across all industries. The nature of risk therefore varies according to the nature of the business

The last reports from the Small and Medium Enterprises Development Agency of Nigeria (SMEDAN) and National Bureau of Statistics collaborative survey (2013) put the total number of SMEs in Osun state at 2,272. It is expected that this number should be able to facilitate and fast tract economic development in the state, based on the role of SMEs in economic growth. However, the reverse is the case as the state still ranks amongst the poor/less developed states in the country, with the government finding it difficult to regularly pay her workers. Since scholars have identified risk management as a major challenge facing SMEs, this study intends to evaluate the effect of risk management practices on the performance of SMEs in Osun state. The study is imperative in order to increase knowledge on risk management and its relevance as it concerns SMEs and the need to increase the performance of SMEs, thereby improving the nation's economy.

\section{Conceptual reviews}

\section{LITERATURE REVIEW}

Vaughan and Vaughan (2001) defines risk management as a scientific approach to dealing with pure risks by anticipating possible accidental losses and designing and implementing procedures that minimize the occurrence of loss or the financial impact of the losses that do occur. The authors further submit that the main objective of risk management is to ensure that the organization is not prevented from achieving its primary objectives as a result of losses that might arise from its operations. The achievement of these objectives usually begins with the performance of the risk management function. Watt (2007) opines that the risk management function in SMEs is usually at the prerogative of the owner. This however means that risk management amongst SME is greatly influenced by the owner's risk perception and his attitude towards risk management (Ntihane, 1995; cited by Smit and Watkins, 2012). In this regard, entrepreneurs should acquire the skills of risk identification, analysis and control. Alternatively, the function of risk management should be assigned to another person with the necessary skills within or outside the enterprise. Risk cannot be managed unless it is first identified. Risk identification involves identifying possible risks that may affect the objective of the business negatively or positively.

Aruwa (2004) defined risk management as an integral part of good business governance. It is simply protecting the business from possible negative occurrences, as well as recognizing opportunities and capitalizing on them when they arise. In addition, Head (2009) defines risk management as the process of planning, organizing, directing and controlling resources to achieve given objectives when good or bad events are possible.

\section{Empirical Reviews}

Inang \& Ukpong (2002) and Aruwa (2004) posited that Small and Medium Enterprises (SMEs) are businesses in the private sector and they cut across all industries. In Nigeria as documented in Odeyemi (2003), "empirical report shows that an estimate of about $70 \%$ of the industrial employment is held by SMEs and more than $50 \%$ of the Gross Domestic Product is 
SMEs generated". SMEs are generally very susceptible and only a certain number of them manage to survive due to several economic, market and financial factors (Oboh 2002; Okpara 2000; Wale-Awe, 2000).

SMEs have a number of significant contributions to the economic growth and development of Nigeria. Ariyo (2008) affirms that "SMEs account for $97 \%$ of all businesses in Nigeria, employ $50 \%$ of Nigeria's workforce and produce $50 \%$ of Nigeria's industrial output". Moreso, "SMEs enhance the distribution of economic growth in a decentralized and more equitable manner, eliminating concentrated areas of population and enable equitable distribution of wealth in an emerging economy" (Nowduri, 2012). Ogechukwu (2011) also affirm that SMEs participate actively in the mobilization of the natural resources and reduce supply in the labour market.

Mead \& Liedholin (cited in Smith and Watkins, 2012) argued that "Small and Medium Enterprises and large firms operate in the same business environment but there are evidences that they derive different benefits and opportunities therein. Moreso, they are exposed to diverse categories of risks. This is because of their differences in economic capacity including asses to human capital and material resources". In addition, Kelkar (2008) noted that SMEs are weak in terms of business plan, management structure and in decision making when compared to large organizations. This further increase SMEs' inability to absorb most business uncertainties and risks. Suh (2010) on the other hand posit that SMEs sector is worst affected by the economic environment and is the first to be hit by any external shock. As a result, there are more SMEs closures than establishments, with approximately only 1 percent of SMEs growing from having five or less employees to ten or more".

While studying the financing options available to SMEs in Nigeria, Azende (2012) focussed on cases in Benue and Nasarawa states and emphasized the need to have good risk management practice as a way of resolving the financing options problems. According to the author, predominant SMEs are lacking in good risk management strategies and insurance cover, thus resulting to substantial financial constraints. In a similar research work in India, Panigrahi (2012) revealed that risk management is a useful process that should be adopted by SMEs to improve their business sustainability and chances of successful longevity. The author also identified lack of risk expertise and understanding of the subject matter of risk management as the reason for the ineffective practice of risk management within the small business sector. Furthermore, the attitudes of the business owners and their knowledge of risks were noted to play essential roles in how systematically risks are handled.

\section{Conceptual Framework}

This study ties together the basic concepts of risk management, proxy by risk identification and attitudes to risk in the context of performance of SMEs Osun state, Nigeria. It argues that the reduction of uncertainty increases the willingness of Small and Medium Enterprises in Nigeria to undertake initiatives.

Figure 1: The effect of Attitude to Risk on Risk Management and the effect of Risk Management proxy by Risk Identification on the performance of SMEs

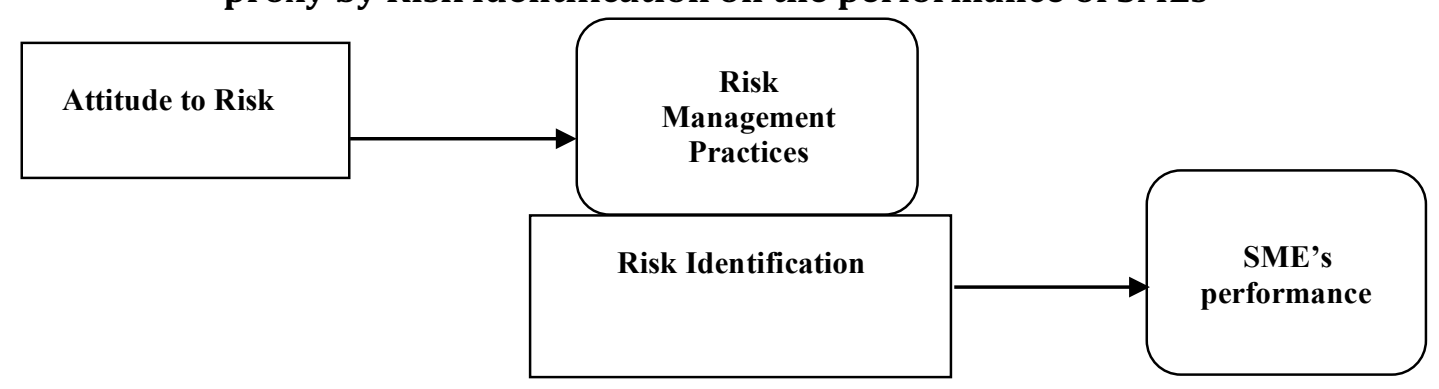

Source: Author's Compilation, 2018 
In Nigeria, emphasis has been placed on the role of government in the enlightening SMEs on the importance of risk management practices and the need for adequate legislation and policy formulation, targeted at improving risk management has been discussed (Terungwa, 2012; Eze and Okoye, 2013), However, little has been discussed on the effect of risk management on the performance of SMEs. This research work is aimed at filling this gap.

The two hypotheses for this study are stated as follows:

Ho1: Risk Identification does not affect the performance of SMEs in Osun state, Nigeria.

Ho2: Attitude to Risk does not affect Risk Management practices amongst SMEs in Osun state, Nigeria.

\section{METHODOLOGY}

The study used a survey design method. Risk Management Practices were measured with subvariables; risk identification and risk monitoring. The Performance of SMEs was measured with the sub-scale of revenue growth. A total of 340 out of a population of 2,272 SMEs in Osun state were chosen for this study, through a purposive sampling technique (SMEDAN and National Bureau of Statistics collaborative survey, 2013). This sample size is in agreement with Yamane (1973) model of sample size determination for a finite population.

Questionnaire used in this study is divided into four parts and involved the 5-point likert-scale. The parts are; Demographic information question items, Risk Identification question item, Attitude to Risk question item and SMEs' performance question items. A validity and reliability test of the questionnaire was conducted, prior to the main study on 10 SMEs, which were not included in the study sample. Cronbach Alpha values ranging from 0.75 to 0.78 were obtained for the variables' items, which made the instrument suitable for the study.

Three hundred and forty (340) SME managers/operators who have been operating in Osun state, Nigeria for more than two years were targeted in this study, out of which 330 of the retrieved responses were considered well filled and suitable for this research. That gave a nonresponse rate of 3 percent, which is acceptable according to Turner (2003), who stated that a 10 percent non-response rate is ideal for data analysis.

Data collected was analyzed qualitatively and quantitatively, through descriptive statistics and the linear regression model. Ordinary least square technique was used to estimate the model, with the aid of the E-view statistical package.

\section{RESULTS AND DISCUSSION}

The result of the extent of correlation between Risk Identification and Risk Management is presented in table 1 . The table shows that this relationship is statistically significant with $\mathrm{p}<0.05$

\begin{tabular}{|l|l|l|}
\hline \multicolumn{2}{|l|}{ Table 1: Pearson Correlation Coefficients, N = 330 } & \\
\hline & Risk Identification & Risk Management \\
\hline Risk Identification & 1.00000 & $\begin{array}{l}0.91601 \\
<.0001\end{array}$ \\
\hline Risk Management practice & $\begin{array}{l}0.91601 \\
<.0001\end{array}$ & 1.00000 \\
\hline
\end{tabular}

Source: Author's computation, through E-view (2018) 
Table 1 shows a strong positive correlation between Risk Identification and Risk Management practices $(r=0.92)$. This implies that an increase in risk identification process by SMEs will result to a corresponding increase in risk management practices. Therefore, Risk Identification can be used as proxy for Risk Management practices amongst SMEs in Osun state, Nigeria.

Test of Hypothesis One

\begin{tabular}{|l|l|l|l|l|l|l|l|}
\hline \multicolumn{2}{|l|}{ Table 2: Summary of Regression Analysis of Risk Identification on performance of SMEs } & \multicolumn{2}{l|}{ Model Summary $^{\text {b }}$} \\
\hline Variable & Label & Parameter Estimate & Standard Error & t Value & Pr $>$ |t| & & \\
\hline Intercept & Intercept & 1.53727 & 0.09669 & 15.90 & $<.0001$ & R-Square & 0.7416 \\
\hline & $\begin{array}{l}\text { Risk } \\
\text { Identification }\end{array}$ & 0.93018 & 0.03963 & 23.47 & $<.0001$ & Adj R-Square & 0.7402 \\
\hline
\end{tabular}

a. Predictors: (Constant), Risk Identification (proxy for Risk Management).

b. Dependent Variable: Performance of SMEs.

Source: Author's computation, through E-view (2018)

Table 2 shows an R-squared value of 74.16 percent, confirming the extent of the relationship that exists between risk management (proxy by risk identification) and the performance of SMEs. The remaining 25.84 percent are other factors that affect the performance of SMEs in the state, but not listed in this model. The estimates of the model coefficients for $\beta_{0}$ (Intercept) is 1.53727, and $\beta_{1}$ (Risk management practice) is 0.93018. Therefore, the estimated model between Risk management practices on the Performance of SMEs is:

\section{SMEs performance $=1.53727+0.93018$ Risk Identification}

This model shows that risk management practice has a positive and significant effect on the performance of SMEs in Osun state. Thus, if risk management practice, through risk identification is improved by 1 unit the average change in the performance of SMEs will increase by 0.93 percent.

\section{Hypothesis One:}

Ho1: Risk Identification does not affect the performance of SMEs in Osun state, Nigeria.

Table 2 shows a t-value of 23.47, which is statistically significant at $p<0.05$. The null hypothesis is therefore rejected in favour of the alternative hypothesis and it is concluded that Risk Identification (as a proxy for Risk Management) affect the performance of SMEs in Osun state.

\section{Test of Hypothesis Two}

\begin{tabular}{|l|l|l|l|l|l|l|l|}
\hline \multicolumn{2}{|l|}{ Tableof Regression Analysis of Risk Identification on performance of SMEs } & \multicolumn{2}{l|}{ Model Summary $^{\mathbf{b}}$} \\
\hline $\begin{array}{l}\text { Table 3: Summary of Regression Analysis of Attitude to Risk on risk management } \\
\text { practices of SMEs }\end{array}$ & \multicolumn{2}{l|}{ Model Summaryb } \\
\hline Variable & Label & Parameter Estimate & Standard Error & t Value & Pr > |t| & & \\
\hline Intercept & Intercept & 0.58030 & 0.08012 & 7.24 & $<.0001$ & R-Square & 0.7847 \\
\hline & $\begin{array}{l}\text { Attitude to Risk of } \\
\text { SMEs }\end{array}$ & 0.82775 & 0.03129 & 26.45 & $<.0001$ & Adj R-Square & 0.7836 \\
\hline
\end{tabular}

a. Predictors: (Constant), Attitude to Risk.

b. Dependent Variable: Risk Management practices.

Source: Author's computation, through E-view (2018) 
In Table 3, the relationship between Attitudes to Risk by SMEs and their risk management practices is explained up to the value of 78.47 percent. The remaining 21.53 percent are other factors that are not captured in the model.

As depicted in Table 3, the estimates of the model coefficients for $\beta_{0}$ (Intercept) is 0.58030 , and $\beta_{1}$ (Attitude to Risk of SMEs) is 0.82775 . Therefore, the estimated model between attitude to risk of SMEs operators and their risk management practices is presented as:

\section{Risk Management practices $=0.58030+0.82775$ Attitude to Risk of SMEs}

The regression equation shows that attitude to risk of SMEs has a positive and significant effect on their risk management practices, with 0.58030 being the average value when both variables are held constant. Furthermore, if SMEs operators improve their attitude to risk by 1 unit there will be a corresponding improvement of $0.83 \%$ in the risk management practices.

\section{Hypothesis Two:}

$\mathrm{Ho}_{2}$ : Attitude to Risk does not affect Risk Management Practices amongst SMEs in Osun state, Nigeria.

Table 3 shows a t-value of 26.45 , which is statistically significant at $p<0.05$. The null hypothesis is therefore rejected in favour of the alternative hypothesis to conclude that Attitude to Risk positively affect Risk Management practices amongst SMEs in Osun state.

The summary of the research findings in this section are that Risk Management significantly affect SMEs' performance and Attitude to Risk positively affect Risk Management practices. These findings are consistent with those of other scholars in Risk Management and SMEs (Henchel, 2008; Panigrahi, 2012; Ioper \& Kwanum, 2012; Pradana \& Bandula, 2012 and Sifumba et al., 2017).

\section{CONCLUSION AND RECOMMENDATIONS}

The main objective of this study was to examine the effect of risk management practices on the performance of SMEs in Osun state. Three hundred and thirty (330) SME operators, who have been operating in Osun state, Nigeria for more than two years were targeted in this study. The result of the simple linear regression analysis used in testing the effect of the independent variable on the dependent variable reveals a significant relationship between Risk management practices (proxy by Risk Identification and Attitude to Risk) and Performance of SMEs in Osun state. Further analysis showed that while attitude to risk positively affect risk management practices, there is a strong positive correlation between risk identification and risk management.

Based on these findings, the study concludes that Risk Management practices have significant and positive influence on the performance of the performance of SMEs in Osun state.

The study recommends that SME operators in Osun state should put in place cost-effective measures for timely risk identification and effective risk mitigation so as to ensure that their financial performance is not impacted negatively. In addition, risk management frameworks such as the Enterprise Risk Management which conform to international best practice, should be put in place. Furthermore, policy makers in the state should put up more stringent policies for SMEs to better manage their risks. 


\section{References}

Aduko, J., (2011). General insurance, a tool for managing business risks: A case study of SMEs in the Tamale Metropolis. Masters Dissertation: Kwame Nkrumah University of science and Technology, Ghana. Retrieved July 15 2014, from http://www.lib.umi.com.

Afolabi, T.S., (2018). Effect of Claims Payments on Profitability in the Nigerian Insurance Industry. Advances in Social Sciences Research Journal, 5(4), 94-101.

Akabueze, B. (2002). Prospectus on Nigeria SMEs under the Small and Medium Industries Investment Scheme (SMIEIS). Accessed August 14, 2009 from www.nigeriabusinessinfor.com/nigerian-smes2000.htm .

Ariyo, D. (2008). Small Firms are the Backbone of the Nigerian Economy. Retrieved online from http:/www.africaeconomyanalysis.org, August 24, 2012.

Aruwa, S.A.S. (2004). Financing Options for Small and Medium-Scale Enterprises in Nigeria. The Nigerian Journal of Accounting and Research, Department of Accounting, Ahmadu Bello University, Zaria, 1(2),

Azende, T. (2012). Risk Management and Insurance of Small and Medium Scale Enterprises (SMEs) in Nigeria. International Journal of Finance and Accounting, 1(1), 8-17.

Boniface, U. and Ibe, I. G. (2012). Enterprise Risk Management and Performance of Nigeria's Brewery Industry. Developing Country Studies, 2(10), 60-67.

Casualty Actuarial Society: (CAS) (2003). Overview of Enterprise Risk Management. Retrieved on July 13, from http:/www.casact.org/research.

Cook, P. and Nixson, F. (2001). Finance and Small and Medium Sized Enterprise Development. Finance and Development research Programme Working Paper, 14.

D’arcy, S. P. and Brogan, J.C. (2001). Enterprise Risk Management. Journal of Risk Management of Korea, 12, 2-4.

Douglas, H. (2009). The Failure of Risk Management: Why it's Broken and How to Fix it. John Wiley.

Eze, O. R. and Okoye, V. (2013). Analysis of Insurance Practices and Economic Growth in Nigeria: Using Cointegration test and Error Correction Model. Global Advanced Research Journal of Management and Business Studies. 2(1), 063-070.

Henschel, T. (2009). Risk Management Practices of SMEs: Evaluating and Implementing Effective Risk Management Systems. Berlin: Enrich SchmitVerlag GMBH\& Co. Hoffman, M. A. (2009). Interest in Enterprise Risk Management is Growing. Business Ins., 43, 14-16.

Inang, E. E. and Ukpong, G.E. (2002). A Review of Small-Scale Enterprises Credit Delivery Strategies in Nigeria. Economic and Financial Review. CBN, 30(4).

Kpelai, T. (2009). Entrepreneurship Development in Nigeria, Makurdi: Aboki Publishers. Mambula, C. (2002). Perceptions of SME Growth Constraints in Nigeria. Journal of Small Business Management, 40 (1), 58-65.

Nowduri, S. (2012). Framework for Sustainability Entrepreneurship for Small and Medium Enterprises (SMEs) in An Emerging Economy. World Journal of Management, 4, 51-66.

Ohanga, M. (2005). Bank Lending Practices to Small and Medium Sized Enterprises. Retrieved

November11,2009from http://www.med.govt.nz/templates/MultipageDocumentPage_971

Panigrahi, A.K. (2012). Risk management in Micro, Small and Medium Enterprises (MSMEs) in India: A Critical Appraisal. Asia Pacific Journal of Marketing \& Management Review, 1(4).

Smit, Y. and Watkins, J.A. (2012). A literature Review of Small and Medium Enterprises (SME) Risk Management Practices in South Africa. Africa Journal of Business Management, 6, 6324-6330.

Spedding, L. and Rose, A. (2008). Business Risk Management Handbook: A sustainable approach. Burlington USA: CIMA Publishing.

Suh, J.D., (2010). Risks and Opportunities Facing SMEs in the Post-crisis Era. APEC SMEs Training Workshop, Taipei, Korea May 24th - 28th, May.

Tajudeen, O. Y. and Francis, S. D. (2013). SMEs, Business Risks and Sustainability in Nigeria. European Journal of Business and Social Sciences, 2(9), 76-94.

Vaughan, E., and Vaughan, T. (2001). Essentials of Risk Management and Insurance. USA, New York: John Willey and Sons.

Watt, J. (2007). Strategic Risk Management for Small Businesses. In Reuvid, J. (Ed.), Managing Business Risk 2nd Edition- a practical guide to protecting your businesses. London-Philadelphia: Kogan page. 